\title{
The discovery of the local flora as reflected in BSBI vice-county datasets - a case study for Berwickshire v.c.81
}

\author{
Michael E. Braithwaite \\ Hawick, Scotland
}

Corresponding author: mebraithwaite@btinternet.com

This pdf constitutes the Version of Record published on $16^{\text {th }}$ September 2021

\begin{abstract}
This paper reviews the achievements of botanical recording in Berwickshire over two centuries with particular reference to populations of locally-scarce plants, using graphs and tables rather than distribution maps. It concludes that, whilst the time available for fieldwork over two centuries has been well spent, it will be desirable to consider how populations of locally-scarce species searched for and not refound are best recorded during the next recording cycle, so that trends in these species become readily available. This might be best achieved by intensive repeat-recording of each site of botanical interest in rotation, preparing a revised site account on completion of each site survey.
\end{abstract}

Key words: locally-scarce plants; monads; BSBI surveys; population losses

\section{Introduction - Berwickshire's botanical recording history}

Berwickshire's botanical recording history is examined using graphs and tables, rather than distribution maps, under the following main sections:

1. An overview

2. All species taken together

3. A selection of three individual species

4. A wider sample of fifteen locally-scarce species

5. Locally-scarce species as a class.

All the data used have been extracted from the BSBI MapMate dataset for Berwickshire v.c.81. These data are also available in the BSBI Distribution Database (https://database.bsbi.org/).

\section{Overview}

As each vice-county has a distinct botanical recording history, a brief overview of Berwickshire's botanical recording history is given by way of introduction. Six date classes are defined, representing distinct phases in that history: 
Date class $1800-1909$

1829 and 1853 - Two county Floras by George Johnston (Johnston, 1829; 1853)

with localities of the scarcer species, biased towards the east of the county. Given the fragmented habitats of Berwickshire, almost all localised records could be allocated to monads ( $1 \mathrm{~km}$ square), but many hill plants were recorded as 'frequent in the Lammermuirs', or similar, and thus remained unlocalised.

1831 to 1909 - Regular reports of botanical discoveries in the History of the Berwickshire Naturalists' Club by an active membership. These reports covered discoveries of species new to the county and additional localities for the scarcer species.

1902 - An annotated check-list for Lauderdale, in the west of the county, by Andrew Kelly and William Shaw (Kelly \& Shaw, 1902).

Date class 1910-1949

A low level of botanical activity. Some wildflower diaries by members of the Wild Flower Society with many records localised to monad-scale sites.

Date class 1950-1969

Recording for BSBI's first Atlas (Perring \& Walters, 1962). Systematic recording at monad scale by Dr Albert Long and his son David, with at least one plant list for a selected site in each hectad (10 km square). A week-long field meeting led by $\mathrm{Dr}$ Franklyn Perring gathered records at hectad scale (not considered here), at monad scale for some botanically-rich sites and at $100 \mathrm{~m}$ scale for some locally-scarce species.

\section{Date class 1970-1986}

Site surveys for the Nature Conservancy Council by Chris Badenoch and for the Scottish Wildlife Trust by myself, resulting in a series of monad-scale plant lists.

Date class 1987-1999

A systematic sample survey at monad scale for the whole vice-county aimed at compiling as complete a list of species as possible for each hectad and recording populations of locally-scarce plants at $100 \mathrm{~m}$ scale. The recording was led by myself but involved numerous groups and individuals.

Date class 2000-2019

2000 to 2006 - Various dedicated site surveys and scarce plant surveys.

2007 to 2013 - A systematic sample survey at monad scale for the whole vice-county aimed at compiling as complete a list of species as possible for each hectad and recording populations of locally scarce plants at $10 \mathrm{~m}$ scale using GPS. The survey was more intensive than the 1987-1999 survey and included many of the monads recorded in 1987-1999 and many other monads where it was thought there might be distinctive species. The recording was led by myself but again involved numerous groups and individuals.

2014 to 2019 - Following my retirement as Vice-County Recorder, Robin Cowe made a series of remarkable discoveries of locally-scarce plants. 


\section{Summary}

Overall, the objectives matured from vice-county scale in the period $1800-1949$, to hectad scale for the first BSBI Atlas and to monad scale thereafter, with more precise localities for the scarcer species. Tetrad $(2 \mathrm{~km})$ scale has not been used. Only those records at monad scale or finer are considered here.

\section{The recording history of all species taken together}

The recording history for all species can be summarised as the sum of the number of distinct monads recorded for each species in Berwickshire (Table 1; Fig. 1). Figure 1 includes an exponential regression line.

Table 1. The sum of the number of distinct monads in which each species has been recorded

\begin{tabular}{|l|r|r|r|r|r|r|r|}
\hline Date class & $\begin{array}{r}\mathbf{1 8 0 0} \\
\mathbf{1 9 0 9}\end{array}$ & $\begin{array}{r}\mathbf{1 9 1 0} \\
\mathbf{1 9 4 9}\end{array}$ & $\begin{array}{r}\mathbf{1 9 5 0} \\
\mathbf{1 9 6 9}\end{array}$ & $\begin{array}{r}\mathbf{1 9 7 0} \\
\mathbf{1 9 8 6}\end{array}$ & $\begin{array}{r}\mathbf{1 9 8 7} \\
\mathbf{1 9 9 9}\end{array}$ & $\begin{array}{r}\mathbf{2 0 0 0} \mathbf{2 0 1 9} \\
\text { Total }\end{array}$ & \\
\hline Distinct monads & 2,930 & 1,976 & 7,053 & 12,035 & 33,073 & 57,134 & 114,201 \\
\hline $\begin{array}{l}\text { Cumulative monads } \\
1800+\end{array}$ & 2,930 & 4,685 & 10,995 & 21,401 & 48,415 & 86,753 & \\
\hline $\begin{array}{l}\text { Refinds in next date } \\
\text { class }\end{array}$ & 221 & 964 & 2,593 & 8,652 & 27,448 & & \\
\hline \% Refinds & 8 & 21 & 24 & 40 & 57 & & \\
\hline $\begin{array}{l}\text { Cumulative monads } \\
1950+\end{array}$ & & & 7,053 & 17,863 & 45,317 & 84,054 & \\
\hline $\begin{array}{l}\text { Refinds in next date } \\
\text { class }\end{array}$ & & & 1,225 & 6,844 & 25,241 & & \\
\hline \% Refinds & & & 17 & 38 & 56 & & \\
\hline
\end{tabular}

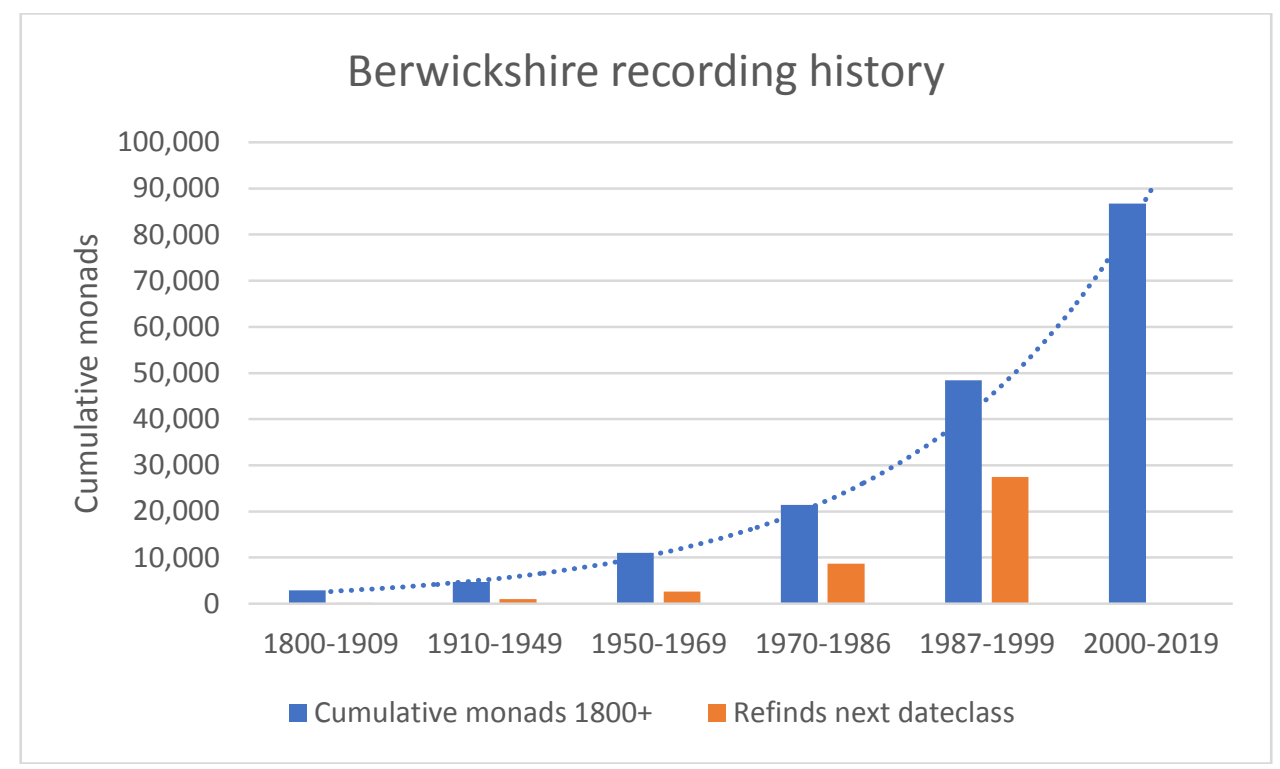

Figure 1. Cumulative recording history 1800-2019

These were sample surveys with no expectation of re-recording all previously recorded monads, so the proportion of refinds, though instructive, is not particularly 
meaningful. It is necessary to turn to individual species to obtain a closer insight into trends in plant populations over time.

\section{The recording history of three individual species}

Three species have been chosen to illustrate contrasting recording histories, Galium boreale, Cirsium heterophyllum and Crepis paludosa (Fig. 2)

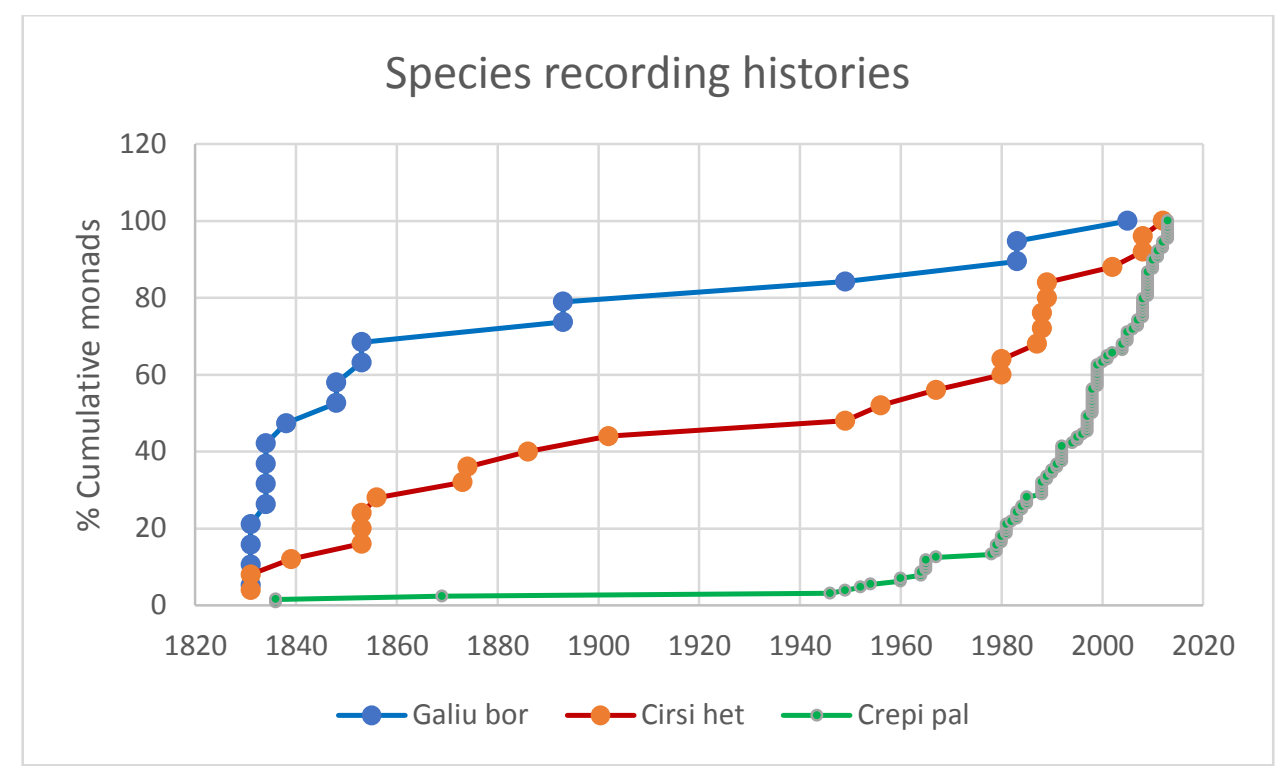

Figure 2. The recording history of three contrasting species

Galium boreale, remarkably, occurred in Berwickshire in damp calcareous grassland in the lowland district of The Merse, but not in the hills. It has been recorded in 19 monads. Populations are treated, for convenience, as being bounded by $1 \mathrm{~km}$ grid lines. Numerous populations were discovered at early dates, but were soon lost to agricultural improvement. There were very few later discoveries.

Cirsium heterophyllum, in contrast, has occurred at scattered localities by the coast, in The Merse and in the hills. Discoveries have been made over a long period. It has been recorded in 25 monads. The record is now considered to be almost exhaustive, but this cannot be deduced directly from the data. It is a subjective assessment from a knowledge of the coverage of suitable habitat. There have been losses, though proportionately many fewer than for Galium boreale.

Crepis paludosa is a much more widespread species and was not localised in Johnston's Floras. More recently it has been classified as an axiophyte and has been recorded in detail. It has been recorded in 128 monads. There is every reason to suppose that there are undiscovered populations. Some decline is suspected, but not substantiated, and some limited colonisation may have been occurring.

\section{A wider sample of fifteen locally-scarce species}

\section{The period 1800-2019}

To investigate how typical the two locally-scarce species Galium boreale and Cirsium heterophyllum are of locally-scarce species as a group, a further thirteen such 
species were chosen, being amongst those that have been well-recorded and have around ten extant populations. These were: Antennaria dioica, Astragalus danicus, Carex laevigata, Carlina vulgaris, Dianthus deltoides, Equisetum telmateia, Hippuris vulgaris, Lathraea squamaria, Sagina nodosa, Rhodiola rosea, Thalictrum minus, Trientalis europaea and Trollius europaeus. The recording history of these chosen species was plotted on charts as before for the period 1800-2019.

It was found that the only species to separate out were those with few recent records, correlating with the statistics of likely losses set out below. Although there was variation between the other species, there was no consistent differentiating pattern. In particular all had several or many recently discovered populations, and indeed there is a repeated pattern of additional populations being discovered throughout the period from 1800 to 2019, albeit at differing dates, with the number of additional populations broadly proportional to the level of recording activity in each date class.

For these fifteen species crude estimates of the proportion of the monad records thought to have survived are given below (Table 2). These estimates enable the species to be ranked. These are much simplified versions of the treatment in Berwickshire's disappearing scarce plants (Braithwaite, 2010) revised in A short Flora of Berwickshire (Braithwaite, 2013).

Table 2. Percentage survival of 15 locally-scarce species

\begin{tabular}{|l|r|r|l|}
\hline Species & $\begin{array}{r}\text { Monad records } \\
\mathbf{1 8 0 0 - 2 0 1 9}\end{array}$ & $\begin{array}{r}\text { \%o } \\
\text { Survival }\end{array}$ & $\begin{array}{l}\text { Survival } \\
\text { Group }\end{array}$ \\
\hline Hippuris vulgaris & 21 & 19 & Low \\
\hline Trollius europaeus & 30 & 20 & Low \\
\hline Galium boreale & 19 & 25 & Low \\
\hline Antennaria dioica & 12 & 31 & Low \\
\hline Trientalis europaea & 14 & 36 & Low \\
\hline Cirsium heterophyllum & 25 & 43 & Medium \\
\hline Dianthus deltoides & 24 & 45 & Medium \\
\hline Sagina nodosa & 20 & 46 & Medium \\
\hline Thalictrum minus & 13 & 54 & Medium \\
\hline Astragalus danicus & 22 & 54 & Medium \\
\hline Lathraea squamaria & 20 & 61 & High \\
\hline Carex laevigata & 14 & 64 & High \\
\hline Carlina vulgaris & 14 & 75 & High \\
\hline Equisetum telmateia & 20 & 76 & High \\
\hline Rhodiola rosea & 9 & 100 & High \\
\hline
\end{tabular}

All the species have suffered losses with the exception of Rhodolia rosea, secure in its sea-cliff habitat. The chart of this species does not stand out from the others as a diligent survey by Angus McBride in 1986, using binoculars from barely accessible vantage points, led to the discovery of several previously unrecorded populations. The only species with a chart that does stand out from the others is Carex laevigata, for which there were no localised records between 1892 and 1992, 
but several records both before and after these dates. Its habitat, on damp burnside banks in open woodland or former woodland, is unremarkable until learned.

The fifteen species have been divided into three groups of five on the basis of the proportion of their populations that have survived, and the data for each group has been merged so that their recording histories can be compared (Fig. 3). For the group of species with low survival about $60 \%$ of their populations had been discovered by 1909 , compared with $40 \%$ for the medium survival group and $30 \%$ for the high survival group. For both the medium survival and high survival groups there have been many discoveries since 1950, with no sign of a reduction that would suggest that there were few further populations to be discovered.

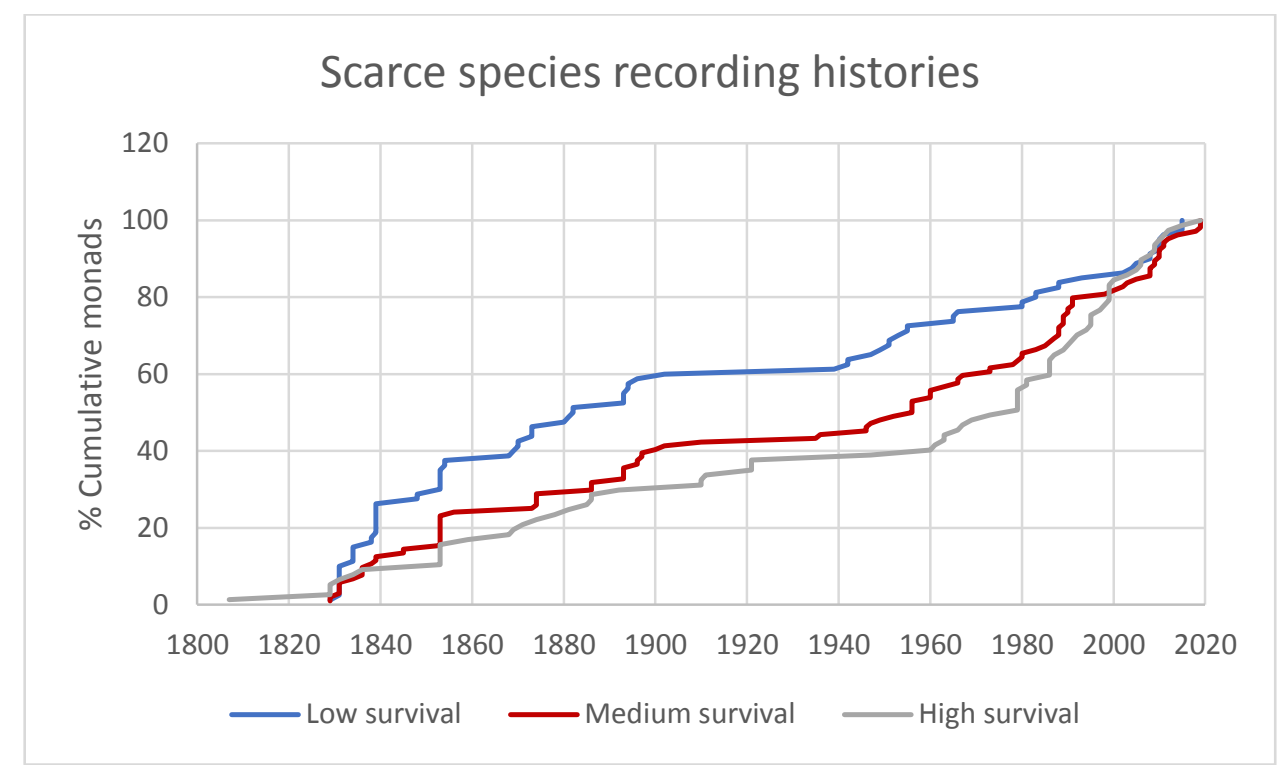

Figure 3. The recording history of three contrasting species-groups 1800-2019

The period 1950-2019

The discoveries since 1950 are clearer when the data is analysed with 1950 (rather than 1800) as a starting point. On this basis the three groups are all but indistinguishable (Fig. 4), though it has been chosen to omit Carex laevigata from the high survival group as it has an anomalous history due to it being overlooked until 1992. Remarkably, the trend of each data series is close to linear despite the variation in the fieldwork over time. These trends relate to discoveries (including any recent colonisation), population losses are not considered.

That it has been possible to maintain the rate of discovery to 2019 reflects the increased intensity of successive surveys. Some of the recent discoveries have been in monads not recorded before, but many of them reflect more thorough recording of well-known sites of botanical interest. Indeed, a prime local objective of the 20002013 field surveys has been to revisit such sites and repeat-record at $10 \mathrm{~m}$ scale populations previously recorded at $100 \mathrm{~m}$ scale.

\section{Locally-scarce species as a class}

For Berwickshire Rare Plant Register 2004 (Braithwaite, 2004) I drew up a list of locally-scarce species on the basis of presence in ten sites or less. Subsequent recording demonstrated that several of these species were more frequent. The 
decision was taken to retain such species as 'scarce' in subsequent publications, in particular Berwickshire BSBI Botanical Site Register 2013 (Braithwaite, 2013). The more-frequent species included several that were colonising forestry and moorland access-roads in abundance, such as Euphrasia micrantha, Lycopodium clavatum and Spergularia rubra.

The data extracted from the MapMate database have been analysed by date class (Table 3).

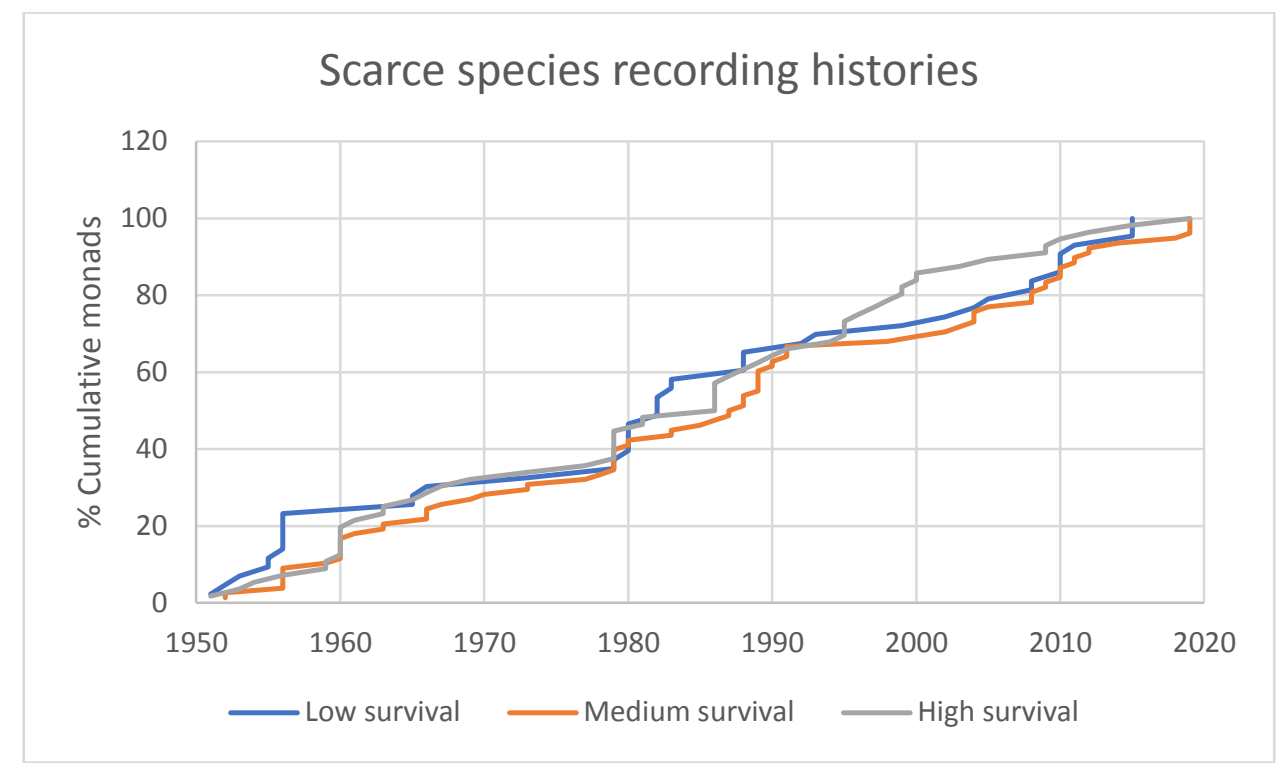

Figure 4. The recording history of three contrasting species-groups 1950-2019

Table 3. The sum of the number of distinct monads recorded for each locallyscarce species

\begin{tabular}{|l|r|r|r|r|r|r|r|}
\hline Date class & $\begin{array}{r}\mathbf{1 8 0 0} \\
\mathbf{1 9 0 9}\end{array}$ & $\begin{array}{r}\mathbf{1 9 1 0} \\
\mathbf{1 9 4 9}\end{array}$ & $\begin{array}{r}\mathbf{1 9 5 0} \\
\mathbf{1 9 6 9}\end{array}$ & $\begin{array}{r}\mathbf{1 9 7 0} \\
\mathbf{1 9 8 6}\end{array}$ & $\begin{array}{r}\mathbf{1 9 8 7} \\
\mathbf{1 9 9 9}\end{array}$ & $\begin{array}{r}\mathbf{2 0 0 0} \\
\mathbf{2 0 1 9}\end{array}$ & Total \\
\hline Distinct monads & 1,023 & 304 & 525 & 472 & 807 & 1,565 & 4,696 \\
\hline $\begin{array}{l}\text { Cumulative monads } \\
1800+\end{array}$ & 1,023 & 1,223 & 1,597 & 1,898 & 2,387 & 3,361 & \\
\hline $\begin{array}{l}\text { Refinds in next date } \\
\text { class }\end{array}$ & 104 & 255 & 426 & 744 & 1,335 & & \\
\hline \% Refinds & 10 & 21 & 27 & 39 & 56 & & \\
\hline $\begin{array}{l}\text { Cumulative monads } \\
1950+\end{array}$ & & & 525 & 897 & 1440 & 2468 & \\
\hline $\begin{array}{l}\text { Refinds in next date } \\
\text { class }\end{array}$ & & & 100 & 364 & 901 & & \\
\hline \% Refinds & & & 19 & 41 & 63 & & \\
\hline
\end{tabular}

Locally-scarce species were preferentially recorded in the Atlas 2000 survey 1987-1999, in dedicated scarce-species surveys 2000-2006, in the Atlas 2020 survey 2007-2013 and in some follow-up survey 2014-2019. For the first time in Berwickshire's botanical recording history, it is possible to say that an almost complete, but inevitably not quite complete, inventory of the populations of locallyscarce species has been obtained, and, in particular, that all historical records of 
locally-scarce species have been searched for. This 1987-2019 inventory could then be compared with earlier date-classes and an indication obtained as to the proportion of the early records of locally-scarce species that had survived (Fig. 5). This is a much-simplified version of the analysis given in Braithwaite (2010) and Braithwaite (2014). The losses are dramatic and appear to have been taking place at a continuously high level throughout the period since 1800 .

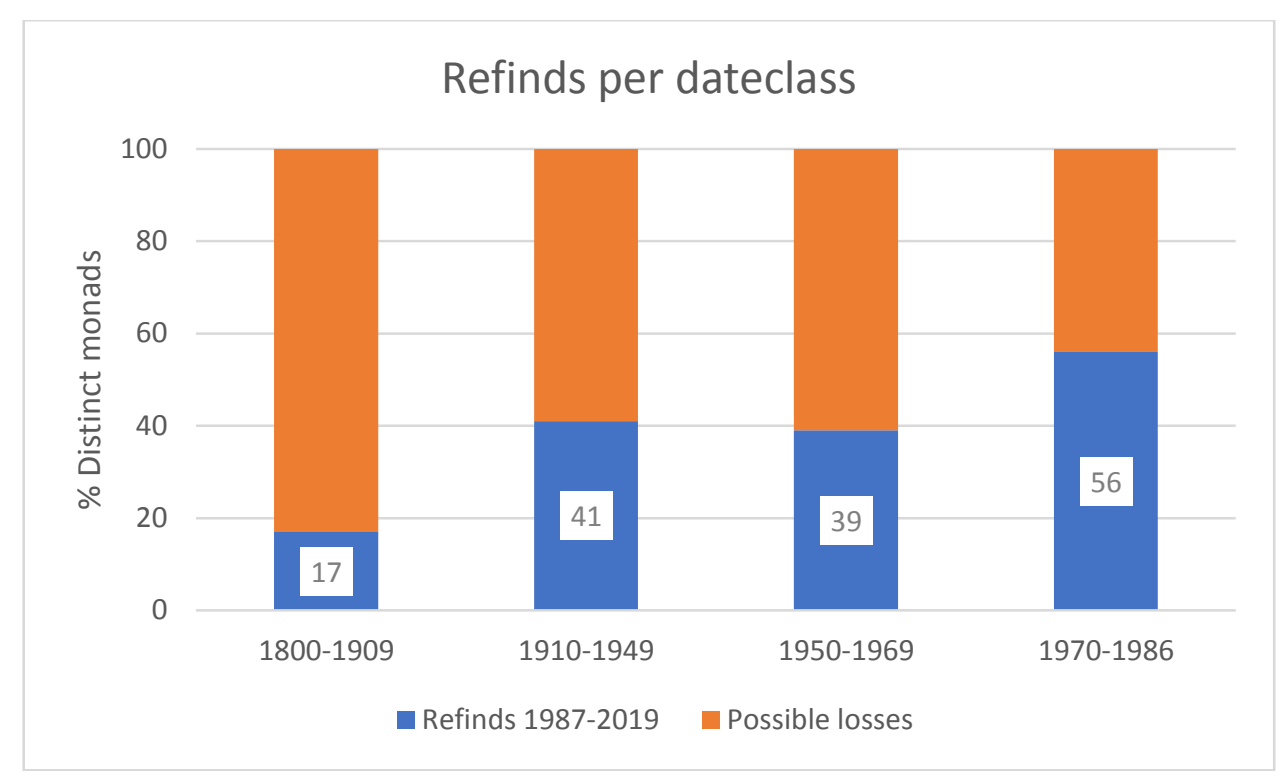

Figure 5. The proportion of populations of locally-scarce species that have been refound in the composite inventory 1987-2019

In order to examine losses between the 1987-1999 date class and the 20002019 date class, records of 448 populations of species expected to be 'site-faithful' that had been recorded in the first date class and searched for in the second date class were analysed in Braithwaite (2014), taking into account an assessment of the probability that each had been overlooked in the second date class. As the surveys had been made in the same hectad-by-hectad rotation in both date classes, the time elapsed between surveys was sixteen years. $21 \%$ of the locally-scarce plant populations were considered to have been lost over sixteen years, or $14 \%$ per decade, or $26 \%$ between the BSBI Atlas 2000 project and the BSBI Atlas 2020 project.

\section{Discussion}

The nineteenth-century recording history for Berwickshire is unusually detailed for a Scottish vice-county. This has enabled insight to be gained on the severe losses that have been suffered among the populations localised at early dates.

The coverage of the more recent sample surveys has increased dramatically. 7,053 distinct monad records were obtained for the first BSBI Atlas (Perring \& Walters, 1962), together with further records at hectad scale not discussed here. 33,073 distinct monad records were obtained for BSBI Atlas 2000 (Preston et al., 2002) and 57,134 for the forthcoming BSBI Atlas 2020. This has led to remarkably even increases in the inventory of locally-scarce species. The diminishing returns to be expected from additional recording have been fully offset by the increased 
intensity of recording. Clearly this cannot be expected to continue. Indeed, my perception, when drawing up the Berwickshire BSBI Botanical Site Register 2013 (Braithwaite, 2013) was that around $90 \%$ of the populations of locally-scarce species had been discovered.

As saturation repeat coverage for historical records of locally-scarce species was achieved by taking the two date classes 1987-1999 and 2000-2019 together, it was relatively straightforward to prepare statistics of population losses for date classes up to 1986 . The more systematic recording in the two most recent date classes has enabled change in a large sample of locally-scarce plant populations to be analysed over a specific time interval of sixteen years. It is to be hoped that similar repeat surveys will be made in the next dateclass. It is emphasised that the losses analysed in this way represent absolute change, not the relative change between groups of species obtained by comparing surveys of different intensities using a statistical adjustment.

For species other than the locally-scarce species, which have been preferentially searched for, there is much still to be discovered. This is as was to be expected after sample surveys. There is probably rather little interest to be gained from an increased coverage of the more widespread species, but much to be learned about some segregates, some hybrids and a variety of neophytes. There is already much scope for repeat-recording, perhaps especially of the sites of botanical interest catalogued in the Berwickshire BSBI Botanical Site Register (Braithwaite, 2013).

\section{Conclusion}

The overall conclusion is that, while the time available for fieldwork over two centuries has been well spent, it will be desirable to consider how populations of locally-scarce species searched for and not refound during the next recording cycle are best recorded, so that trends in these species become readily available. This might be best achieved by intensive repeat-recording of each site of botanical interest in rotation, preparing a revised site account on completion of each site survey.

\section{References}

Braithwaite, M.E. 2004. Berwickshire Vice-county Rare Plant Register. Privately published but PDF available at https://bsbi.org/berwickshire

Braithwaite, M.E. 2010. Berwickshire's disappearing scarce plants. Watsonia 28: 129-140. http://archive.bsbi.org.uk/Wats28p129.pdf

Braithwaite, M.E. 2013. Berwickshire BSBI Botanical Site Register. Privately published. Also available as a PDF at https://bsbi.org/berwickshire

Braithwaite, M.E. 2014. A short Flora of Berwickshire. Privately published. Available as a PDF at https://bsbi.org/berwickshire

Johnston, G, 1829, 1831, A Flora of Berwick-upon-Tweed. Edinburgh: J Carfrae and Son, and London: Longman.

Johnston, G. 1853. The Natural History of the Eastern Borders. London: J van Voorst.

Kelly, I.A. and Shaw, W. Botany, In: Thomson, A. 1902. Lauder and Lauderdale, 313-341, Galashiels: Craighead Bros.

Perring, F.H. \& Walters, S.M. 1962. Atlas of the British Flora. London: Botanical Society of the British Isles. 
Preston, C.D., Pearman, D.A., \& Dines, T.D., eds. 2002. New Atlas of the British and Irish Flora. Oxford: Oxford University Press.

Copyright retained by author(s). Published by BSBI under the terms of the Creative Commons Attribution 4.0 International Public License.

ISSN: $2632-4970$

https://doi.org/10.33928/bib.2021.03.279 